Journal of Patient-Centered

\title{
Giving Credence to the Experience of X-Linked Hypophosphatemia in Adulthood: An Interprofessional Mixed- Methods Study
}

\author{
Melissa Hughes \\ Carolyn Macica \\ Catherine Meriano \\ Maya Doyle
}

Follow this and additional works at: https://aah.org/jpcrr

Part of the Endocrine System Diseases Commons, Musculoskeletal, Neural, and Ocular Physiology Commons, Occupational Therapy Commons, Physical Therapy Commons, Primary Care Commons, and the Social Work Commons

\section{Recommended Citation}

Hughes M, Macica C, Meriano C, Doyle M. Giving credence to the experience of X-linked hypophosphatemia in adulthood: an interprofessional mixed-methods study. J Patient Cent Res Rev. 2020;7:176-88. doi: 10.17294/2330-0698.1727

Published quarterly by Midwest-based health system Advocate Aurora Health and indexed in PubMed Central, the Journal of Patient-Centered Research and Reviews (JPCRR) is an open access, peer-reviewed medical journal focused on disseminating scholarly works devoted to improving patient-centered care practices, health outcomes, and the patient experience. 


\title{
Giving Credence to the Experience of X-Linked Hypophosphatemia in Adulthood: An Interprofessional Mixed-Methods Study
}

\author{
Melissa Hughes, BA, ${ }^{1}$ Carolyn Macica, PhD,${ }^{1}$ Catherine Meriano, JD, OTR, ${ }^{2}$ Maya Doyle, $\mathrm{PhD}^{3}$ \\ ${ }^{1}$ Frank H. Netter MD School of Medicine, Quinnipiac University, North Haven, CT; ${ }^{2}$ Occupational Therapy, School \\ of Health Sciences, Quinnipiac University, North Haven, CT; ${ }^{3}$ Social Work, School of Health Sciences, Quinnipiac \\ University, North Haven, CT
}

\begin{abstract}
Purpose $\quad$ X-linked hypophosphatemia $(X L H)$ is a rare $X$-linked dominant metabolic bone disease, often diagnosed in childhood but causing increasing physical debilitation and pain in adulthood. Physical comorbidities of $\mathrm{XLH}$ in adulthood include pervasive and early-onset degenerative arthritis, mineralizing enthesophytes and osteophytes, osteomalacia and pseudofracture, dental abscesses, and hearing loss.
\end{abstract}

Methods This mixed-methods analysis included physical findings, diagnostic imaging, occupational and physical therapy assessments, and semi-structured interviews by social work to understand the functional outcomes and lived experience of XLH in adulthood, through connections between qualitative data obtained by social work and occupational therapy with the quantitative findings from other disciplines.

Results Three primary themes of chronic pain, fear of falling, and lack of credence given by health care providers emerged from qualitative data and could be correlated with physical findings from functional outcome assessments These concerns contrasted with resilience, adaption, and compensation demonstrated by participants.

Conclusions While new treatments may ease the burden of disease for adults with XLH, further research, increased provider awareness and education, and further development of standards of care are needed to promote accurate and adequate assessment and intervention for adults with XLH. ( $J$ Patient Cent Res Rev. 2020;7:176-188.)

Keywords X-linked hypophosphatemia; endocrine; musculoskeletal; occupational therapy; physical therapy; social work; pain; providers

X -linked hypophosphatemia (XLH), an $\mathrm{X}$-linked dominant ${ }^{1}$ metabolic disease, is the most common of the hereditary phosphatewasting disorders, with an approximated prevalence of 1 in $20,000 . \cdot^{2-5}$ XLH arises as a result of an inactivating mutation of the PHEX gene and is characterized by childhood rickets and defective bone mineralization. ${ }^{6,7}$ PHEX regulates levels of the circulating phosphateregulating hormone FGF23. ${ }^{8,9}$ Dysregulation of FGF23

Correspondence: Maya Doyle, PhD, Quinnipiac University, 275 Mount Carmel Ave., Hamden, CT 06518 (mhdoyle@quinnipiac.edu) results in renal phosphate-wasting and diminished intestinal reabsorption. ${ }^{10}$

A lifelong metabolic disease, common nomenclature adopted for XLH in the literature is "vitamin D-resistant rickets" or "X-linked dominant hypophosphatemic rickets." $"$ B,7 terms characterize the pediatric disorder of deficient mineralization at the growth plate, which may contribute to the inaccurate perception of $\mathrm{XLH}$ as a childhood disorder. Years after growth plate closure, musculoskeletal comorbidities continue to dominate the clinical picture of the adult disorder. ${ }^{6}$ The cumulative impact of phosphate-wasting persists into adulthood and can cause complications, including dental abscess formation without caries, mineralizing 
enthesopathies (bone spurs), degenerative arthritis, marginal osteophyte formation, persistent osteomalacia, spontaneous fractures, and hearing loss. ${ }^{6,11-13}$

Given the complexity and spectrum of the adult disorder and relatively limited controlled studies in this area, including joint replacement surgery for degenerative arthritis, ${ }^{14}$ there is no current standard of care. Treatment goals using standard phosphate supplementation and calcitriol for adults include healing postfracture or following orthopedic surgery, management of persistent osteomalacia (softening of bone), and reduction of pain. ${ }^{6}$ Treatment alternatives include a newly available biologic drug, burosumab, a humanized monoclonal antibody directed at FGF23. ${ }^{15}$ A recent burden-of-disease survey including 232 adults with XLH revealed the impact of XLH: the disease does not end in childhood; and symptoms and related musculoskeletal comorbidities begin early in life and lead to significant and progressive complications that significantly impede activities of daily living, apparent already in the second decade of life. ${ }^{11,16}$ Quality of life is impaired, even in comparison to those with conditions with similar physical manifestations. ${ }^{17}$

The current study provides a comprehensive account of the experiences of adults with XLH using qualitative thematic analysis. It also correlates qualitative data with quantitative findings related to the physical manifestations common to adults with XLH. Study goals were to build theory about the experience of the disease in the affected adult population, particularly why/how individuals with XLH engage with health care providers and services, and to identify common themes that relate to and prevent effective management for this population.

\section{METHODS}

\section{Study Design}

An interprofessional team, including physicians, diagnostic imaging, physical therapy (PT), occupational therapy (OT), and social work, undertook a functional outcomes study to assess gait, range of motion, and functional skills in order to understand the adult patient experience of XLH and to identify the health status and intervention needs of adults with XLH. Key physical and functional findings are reported in the adjunct arm of this study, which was conducted with age- and sexmatched controls. ${ }^{18}$ Briefly, these studies confirmed the global and bilateral presence of enthesophytes of mechanically loaded fibrocartilaginous tendon/ ligament insertion sites, significant loss of cartilage, and osteophytes typical of progressive degenerative arthritis. These findings correlated with significant restriction in range of motion and deviations in gait, consistent with a Trendelenburg-like gait. ${ }^{18}$

In addition to physical findings, qualitative data were obtained through interviews by social work and OT. While questionnaire data were collected online or by mail via surveys, assessments such as Berg balance score, gait analysis, and interviews were completed in a day-long, on-site visit. Physical and radiographical data for adults with XLH and sex/age-matched controls were obtained concurrently. ${ }^{18}$ In the current mixed-methods analysis, themes emerging from qualitative analysis of social work and OT interviews were first corroborated with intake surveys, triangulated by confirmation with participants, and then correlated with physical findings (Table 1).

\section{Participants}

The study was approved by the human experimentation committee/institutional review board at Quinnipiac University. All subjects provided written informed consent prior to screening. Participants consisted of 9 individuals and included male $(\mathrm{n}=5)$ and female $(n=4)$ adults between 43 and 65 years of age $(53.6 \pm$ 5.4 years) with a confirmed diagnosis of XLH as well as age-approximated, sex-matched controls. Eligibility was determined with a questionnaire regarding age (40-65 years), XLH status, physical activity, and medical history. Eligible individuals were invited to participate in the study.

Inclusion criteria included self-reported enthesopathy and degenerative arthritis (major adult comorbidities of XLH), consent to a full-body X-ray to confirm physical status, and assessment of gait and range of motion. Participants agreed to semi-structured interviews by social work and OT. Exclusion criteria included individuals unable to independently walk a distance of 200 feet while on flat stable terrain (indoors) without use of an assistive device, those previously diagnosed with vertigo, and those with adhesive tape allergy used in gait analysis. As such, more severely impacted individuals were excluded from the study. Those who required assistive walking devices outdoors or on unfamiliar and unstable ground were not excluded. 
Table 1. Interview Guides and Assessments

\begin{tabular}{|c|c|c|c|}
\hline Diagnostic Imaging & Physical Therapy & Social Work & Occupational Therapy \\
\hline $\begin{array}{l}\text { Full-body X-rays were } \\
\text { conducted to radiographically } \\
\text { assess bone, joints, and } \\
\text { entheses of each study } \\
\text { participant. }\end{array}$ & $\begin{array}{l}\text { Measurement of the } \\
\text { passive range of motion } \\
\text { bilaterally of the hip, } \\
\text { knee, ankle, and } \\
\text { cervical spine using } \\
\text { a gravity-dependent } \\
\text { goniometer. } \\
\text { Lower Extremity } \\
\text { Functional Scale } \\
\text { (LEFS) } \\
\text { Activities-Specific } \\
\text { Balance Confidence } \\
\text { (ABC) Scale }\end{array}$ & $\begin{array}{l}\text { Psychosocial questionnaire } \\
\text { (adapted from DASS, SF-36, } \\
\text { and CAHPS }{ }^{\circledR} \text { surveys }{ }^{19-21} \text { ) } \\
\text { Semi-structured interview: } \\
\text { - How do you think about } \\
\text { your XLH at this point in } \\
\text { your life? } \\
\text { - How do you think about } \\
\text { your body? } \\
\text { - How does or has XLH } \\
\text { impacted decisions you've } \\
\text { made in your in your life? } \\
\text { - Prompt for details - Daily } \\
\text { activities? Social life? } \\
\text { School? Relationships? } \\
\text { Family planning? } \\
\text { - Are you in contact } \\
\text { with other people with } \\
\text { XLH? What are those } \\
\text { relationships like? } \\
\text { - What are your biggest } \\
\text { concerns right now? }\end{array}$ & $\begin{array}{l}\text { Disabilities of the Arm, Shoulder, } \\
\text { and Hand questionnaire (DASH) } \\
\text { Canadian Occupational } \\
\text { Performance Measure (COPM) } \\
\text { - Step 1: Patient identifies } \\
\text { problems in performance of } \\
\text { daily activities } \\
\text { - Step 2: Patient determines } \\
\text { priorities by rating the importance } \\
\text { of each problem on a 10-point } \\
\text { scale from "not important at all" } \\
\text { to "extremely important" } \\
\text { - Step 3: Based on step 2, the } \\
\text { patient identifies the } 5 \text { most } \\
\text { important problems (highest } \\
\text { rated) } \\
\text { - Step 4: For each of these } \\
\text { prioritized items, the patient } \\
\text { rates on a 10-point scale the } \\
\text { performance from "not able to } \\
\text { do it at all" to "able to do it } \\
\text { extremely well" } \\
\text { - Step 5: For these same items, } \\
\text { the patient rates their satisfaction } \\
\text { from "not satisfied at all" to } \\
\text { "extremely satisfied" }\end{array}$ \\
\hline
\end{tabular}

CAHPS, Consumer Assessment of Healthcare Providers and Systems; DASS, Depression Anxiety Stress Scales;

SF-36, 36-item Short Form Health Survey; XLH, X-linked hypophosphatemia.

\section{Data Collection}

Prior to the on-site visit, participants completed a questionnaire regarding work and activities, pain, anxiety, stress, depression, quality of life, insurance coverage, and satisfaction with health care. Questions were adapted from the Depression Anxiety Stress Scales (DASS), ${ }^{19}$ version 2 of the 36-item Short Form Health Survey (SF-36), ${ }^{20}$ and the Consumer Assessment of Healthcare Providers and Systems $\left(\mathrm{CAHPS}^{\circledR}\right)^{21}$ Clinician and Group Adult Visit Survey and incorporated into a single psychosocial questionnaire. These scales have been used in studies of adults with chronic pain/mobility limitations, such as those with rheumatoid arthritis. ${ }^{19,20}$ Participants were also mailed Disabilities of the Arm, Shoulder, and Hand (DASH), ${ }^{22}$ a 30-item self-report questionnaire designed to assess musculoskeletal disorders of the upper limbs.
Based on these data, review of the XLH literature, and discussions with content experts in the field, an interview guide of open-ended questions was created for use by social work (Table 1). On the day of the site visit, qualitative semi-structured interviews were conducted by social work. In addition, interviews were conducted by OT, reviewing the DASH survey and the Canadian Occupational Performance Measure ${ }^{23}$ (COPM). The standardized COPM utilizes a 5-step process with openended questions to assess individual, client-identified problem areas in daily function (Table 1). All interviews were audio-recorded and transcribed by a professional transcription service or the research team.

\section{Data Analysis}

Data analysis for this mixed-methods study was completed in several phases (Figure 1). Prior to data analysis, transcripts were anonymized and given a participant number to reduce interviewer bias and to further protect 
confidentiality. Thematic analysis included open coding to identify themes and categories, codebook creation, constant comparative analysis, memoing, and selective coding to clarify emerging codes.

The original social work interviewers and OT student observers took part in the first round of open coding. Initial codebooks were created separately by the lead investigators of the social work and OT teams. Codes were discussed and compared within each disciplinary research team to identify emerging salient themes and categories. ${ }^{24,25}$ These two codebooks were then combined and edited, comparing and defining overlapping and emerging themes.

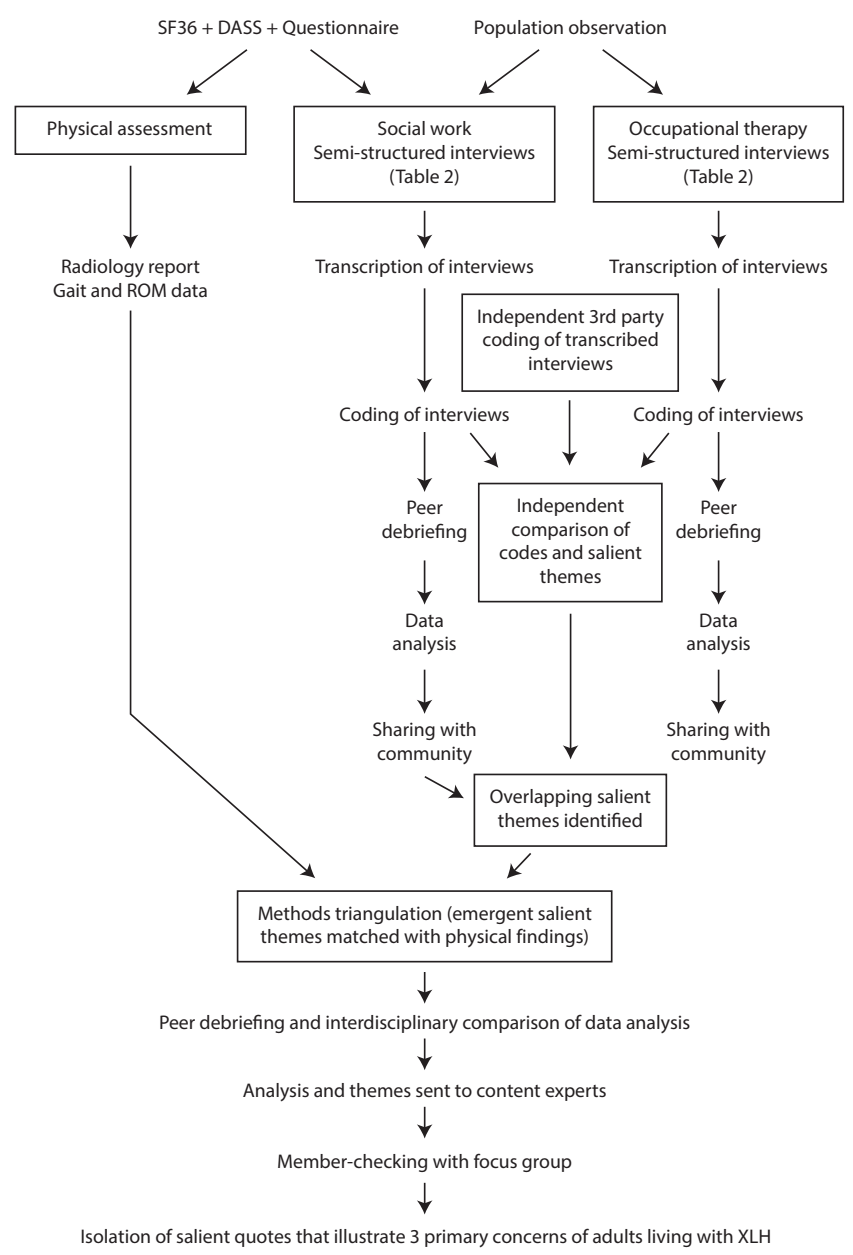

Figure 1. Flow chart illustrating study methods for data collection and analysis. ROM, range of motion; $X L H, X$-linked hypophosphatemia.
In the current mixed-methods analysis, double-blinded findings from the conjoint codebook were further analyzed through comparison with quantitative data from the psychosocial questionnaire and the DASH, and with physical findings from diagnostic imaging and PT and OT assessments (Figure 1 and Table 1). For this analysis, a composite score for the ActivitiesSpecific Balance Confidence (ABC) Scale $^{26}$ was created for each participant to assess confidence in activities performed at home, those requiring travel/ transportation, and in public.

\section{Strategies for Rigor}

Several strategies for rigor $^{5}$ were employed, including peer debriefing between and within interprofessional research teams, methods triangulation (among qualitative and quantitative researchers), and data triangulation (of interview, survey, and physical findings). Member checking was performed with all participants regarding themes in the initial OT codebook, and later by the first author with 2 participants at an XLH patient advocacy event, with consent, after the initial site visit. Rigor was further enhanced by prolonged engagement and persistent observation on the day of data collection and at advocacy events to strengthen understanding of the themes identified through constant comparative analysis. Reporting of qualitative data follows the standards described in the report by O'Brien et al. ${ }^{27}$

Supporting quotes are presented thematically in a supplemental table, without reference to age, gender, or any identifying information, to preserve confidentiality in this rare disease community. Due to the small sample size and variability in survey completion and responses to open-ended questions during semistructured interviews, data about the participant group are reported in numbers, not as percentages.

\section{RESULTS}

Three concerns of adults living with XLH emerged through the iterative process: persistent pain, fear of falling, and lack of credence from the health care team. Themes of resilience, tenacity, and creative approaches to accommodating their increasing debilitation emerged alongside these concerns. The study included 9 participants ( 5 male, 4 female) whose average age was 53.6 years (standard deviation: 5.4 years) and whose median age at XLH diagnosis was 4 years. The impact 
of these themes on daily activities, socialization, and family- and work-related decisions is described herein.

\section{Persistent Pain}

All participants described persistent, at times debilitating, pain impacting every aspect of their lives. The perceived origin of pain was diverse; was associated with bone, muscle, joint, and soft tissue; and varied over the course of the disorder. Participants reported abnormal calcifications (enthesophytes/osteophytes) were among the most distressing kinds of pain.

Many participants were advised to lose weight to reduce pain but felt it was an unsuccessful cycle. Despite current and persistent pain, some participants reported forcing themselves to exercise in the hopes of diminishing their future pain.

Continually living with pain led one participant to question the validity of currently used pain scales. A downside of acceptance or tolerance of pain was, at times, a minimization of the serious etiology of pain, particularly fractures. During this study, 6 of 9 participants had fractures present during the exam and 2 of 9 participants were noted on diagnostic imaging to have fractures they were unaware of (Table 2).

Three-quarters of participants reported XLH directly impacted their respective career paths, and pain was a driving factor in career choice and the age of retirement, often prematurely. Choices around pharmaceutical pain management, including over-the-counter nonsteroidal anti-inflammatory drugs and prescribed medications, and the adequacy of pain management also impacted decision-making. More than half of participants reported XLH directly impacted their decision to have a child. Pain influenced family planning, both in assessing their own ability to parent or out of concern for their child also being diagnosed with XLH.

Pain was often correlated with fatigue (the experience of pain either made fatigue worse or fatigue made the experience of pain worse). This persistent correlation affected the daily activities, choices, and accomplishments of the vast majority of participants. Pain and fatigue limited the time and energy participants could give to any activity in their daily lives, from working, playing with their children, or getting to health care appointments. Overall, participants'
Table 2. Self-Report and Physical Findings of Symptoms and Incidents Related to X-Linked Hypophosphatemia (XLH)

\begin{tabular}{lc}
\hline Self-report of: & Incident/n \\
\hline Bone pain & $9 / 9$ \\
Arthritis and bone spurs (enthesophytes) & $9 / 9$ \\
Bony cysts in hands or feet & $7 / 9$ \\
Spinal stenosis & $5 / 9$ \\
Physical findings - fractures present at & $6 / 9$ \\
site visit & \\
Physical findings - unreported/unaware & $2 / 9$ \\
of fractures present at site visit & $8 / 8$ \\
Bone fracture from or causing a fall & $6 / 7$ \\
$\begin{array}{l}\text { Surgery as result of fall } \\
\text { Early retirement/Condition required }\end{array}$ & $5 / 7$ \\
leaving work & $4 / 6$ \\
Labeled/Told they were "drug-seeking” & \\
Reported providers who were unable to & $9 / 9$ \\
appropriately treat them & $4 / 6$ \\
Fear of falling* & $2 / 4$ \\
Fear of falling impacting social activities* & \\
Have or are using ambulatory assistive & \\
device (cane, walker, etc) & \\
\hline
\end{tabular}

*During psychosocial interviews, incidents emerged related to fear of falling based on questions about daily activities and social life and how XLH impacted decisions; no prompts were used regarding fear of falling.

primary concerns were not the onset or timing of pain but rather how severe the pain might be in a given moment as well as the potential impact of missing a planned event or activity versus enduring pain.

\section{Fear of Falling}

The second theme, fear of falling, was defined by participants as a gradually developing pervasive fear, most often preceded by a fall that resulted in bone fracture, at times necessitating surgery. Incidents related to fear of falling emerged based on questions about daily activities and social life and how XLH impacted decisions; no prompts were used regarding fear of falling. Fear of falling prevented individuals from attending social or work gatherings, interfered with activities of daily living, and/or promoted an early retirement. Participants did not report falls to be due to dizziness/vertigo, syncope, or loss of balance. Those 
who reported falls associated with fractures were unsure if the fractures resulted from the fall or if they fell as a result of spontaneous fracture.

Participants described a fear of falling despite Berg balance scores $^{28}$ within the normal 95\% confidence interval range of predicted values. These fears aligned with the findings of the composite scores on the ABC assessment completed by PT (Table 3). Two participants who reported that fear of falling (Table 2) directly prevented them from attending social activities also scored less than $40 \%$ for confidence in public. Of the 7 respondents who discussed a fear of falling, all experienced at least 1 past fracture and 6 underwent a surgery as a direct result of a fall. Those who scored less than $50 \%$ confidence on $\mathrm{ABC}$ reported more broken bones as a result of a fall. Greater range of motion on physical exam correlated with greater confidence as measured by composite ABC scores, both at home and in public.
All participants in this study reported the greatest confidence in their abilities when at home and the lowest confidence when in public. Traveling, even locally, also was worrisome. Participants described how these fears changed their confidence and participation in activities (online-only Supplemental Table S1).

Most participants reported having an assistive device such as a cane or walker (Table 2), while 6 participants noted using theirs primarily during high-risk activities — in crowds, in the supermarket, or on uneven ground. Though scores on the DASS scale ${ }^{29}$ for anxiety all fell within the normal range (Table 4), participants directly connected their reports of anxiety to their fear of falling (and the fear of further debilitation in their future). One participant noted how they had been referred for behavioral/mental health services due to anxiety and "paranoia" about falling and felt the provider did not understand the very real risk of injury, reporting "I' $m$ afraid of falling, but it's not an irrational fear."

Table 3. Activities-Specific Balance Confidence (ABC) Scale: Composite Scores

\begin{tabular}{|c|c|c|c|}
\hline Participant & Home & Transport & Public \\
\hline $\begin{array}{l}\text { On a scale of } 0 \text { to } 100 \text {, how } \\
\text { confident are you to be able to... }\end{array}$ & $\begin{array}{l}\text { - walk around the house; } \\
\text { walk up/down stairs at } \\
\text { home } \\
\text { - bend over + pick up slipper } \\
\text { from front of closet floor } \\
\text { - reach for a small can at } \\
\text { eye level } \\
\text { - stand on tiptoes + reach } \\
\text { for something overhead; } \\
\text { stand on chair + reach for } \\
\text { something } \\
\text { - sweep the floor } \\
\text { - walk outside house to } \\
\text { parked car in driveway }\end{array}$ & $\begin{array}{l}\text { - get in/out of car } \\
\text { - walk across parking lot } \\
\text { to mall } \\
\text { - walk up/down ramp }\end{array}$ & $\begin{array}{l}\text { - walk in a crowded mall where } \\
\text { people walk rapidly past you } \\
\text { - are bumped into by people } \\
\text { as you walk through mall } \\
\text { - step onto/off escalator WHILE } \\
\text { holding onto railing } \\
\text { - step onto/off escalator } \\
\text { WITHOUT holding onto railing } \\
\text { because of holding bags } \\
\text { - walk outside on icy sidewalks }\end{array}$ \\
\hline Scores by Participant & Home & Transport & Public \\
\hline $\mathrm{P} 1$ & 73.8 & 93.3 & 63 \\
\hline P2 & 66.3 & 50 & 32 \\
\hline P3 & 85 & 86.7 & 64 \\
\hline $\mathrm{P} 4$ & 36.3 & 63.3 & 26 \\
\hline P5 & 93.8 & 100 & 88 \\
\hline P6 & 61.8 & 66.7 & 20 \\
\hline $\mathrm{P} 7$ & 61.3 & $50^{*}$ & * \\
\hline P8 & 80 & 63.3 & 32 \\
\hline P9 & 70 & 56.7 & 40 \\
\hline Mean for all participants & 69.8 & 70 & 45.6 \\
\hline Mean for controls & 99 & 100 & 98 \\
\hline
\end{tabular}

${ }^{*}$ For study participants, a >30\% confidence interval difference was found between scores in activities in the home versus in public. 


\section{Lack of Credence}

The third emerging theme was lack of credence, defined as the patient's perception of a health care provider's unwillingness to appreciate their selfreported symptoms or concerns. All participants reported experiencing a lack of credence from multiple members of their health care team (physicians, OT, PT, nurses, etc) at different points in the course of their disease. Nearly all described how selecting health care providers required a number of attempts to find a provider either familiar with XLH or admittedly unfamiliar but willing to learn. Participants were willing to "stick with" practitioners unfamiliar with XLH if they espoused a willingness to learn. Unfortunately, almost all participants reported more than one experience in which a health care professional challenged their reported symptoms (eg, bone pain) or questioned their diagnosis of XLH.

Participants expressed concern about taking advice from providers who were not knowledgeable about XLH. They also described the process by which they chose which symptoms to report at any given visit so the provider would recognize (and believe) their concerns and not be overwhelmed by their needs in a given visit (Figure 2 and Supplemental Table S1). There is often a perception, from the patient or the provider perspective, that little can be done for the pain. Also of concern to participants was the response they might receive when reporting pain, that providers may label them as inappropriately drug-seeking.

The experience of changing sites or types of pain, or migratory pain, particularly when time elapsed between appointment scheduling and visit, contributes to the perception of patients as unreliable narrators. This lack of credence was reported as inappropriate questioning of the patient and hesitation to treat, or adequately treat, the patient. Participants reported feeling frustration, anger, blame, and a growing lack of confidence in their provider or team. The impact of these experiences resulted in subsequent underreporting of symptoms by the patient. Some participants described how then they began to doubt the accuracy of their own symptoms and narrative as well as feel unsure how to best prioritize reporting

Table 4. DASS and SF-36 Scores (Mean \pm SD) for X-Linked Hypophosphatemia (XLH) Participants and Community Samples

\begin{tabular}{|c|c|c|}
\hline DASS Scores (Scale: 0-42)a & XLH Participants & $\begin{array}{c}\text { From General } \\
\text { Community Sample }^{6}\end{array}$ \\
\hline Depression & $6.3 \pm 3.9$ & $5.1 \pm 7.6$ \\
\hline Anxiety & $4.1 \pm 4.5$ & $3.4 \pm 5.1$ \\
\hline Stress & $6.1 \pm 3.4$ & $8.2 \pm 8.4$ \\
\hline SF-36 Scores (Scale: 0-100) ${ }^{b}$ & XLH Participants & $\begin{array}{c}\text { Baseline From Medical } \\
\text { Outcomes Study }\end{array}$ \\
\hline Physical functioning & $37.9 \pm 17.5$ & $70.6 \pm 27.4$ \\
\hline Role limitations (physical health) & $32.1 \pm 37.4$ & $52.9 \pm 40.8$ \\
\hline Pain & $35.0 \pm 19.1$ & $70.8 \pm 25.5$ \\
\hline General health & $45.7 \pm 13.4$ & $56.9 \pm 21.1$ \\
\hline Physical Component Score & $37.7 \pm 18.4$ & \\
\hline Emotional well-being & $74.9 \pm 13.2$ & $70.4 \pm 21.9$ \\
\hline Role limitations (emotional problems) & $57.1 \pm 46.0$ & $65.8 \pm 40.7$ \\
\hline Vitality/Energy & $45.0 \pm 21.4$ & $52.2 \pm 22.4$ \\
\hline Social functioning & $57.4 \pm 21.4$ & $87.7 \pm 25.4$ \\
\hline Mental Component Score & $58.6 \pm 19.6$ & \\
\hline Health change (perceived over 1 year) & $39.3 \pm 9.7$ & $59.1 \pm 23.1$ \\
\hline
\end{tabular}

${ }^{a}$ higher score $=$ more negative self-assessment.

${ }^{b}$ higher score $=$ more positive self-assessment.

DASS, Depression Anxiety Stress Scale; SD, standard deviation; SF-36, 36-item Short Form Health Survey. 


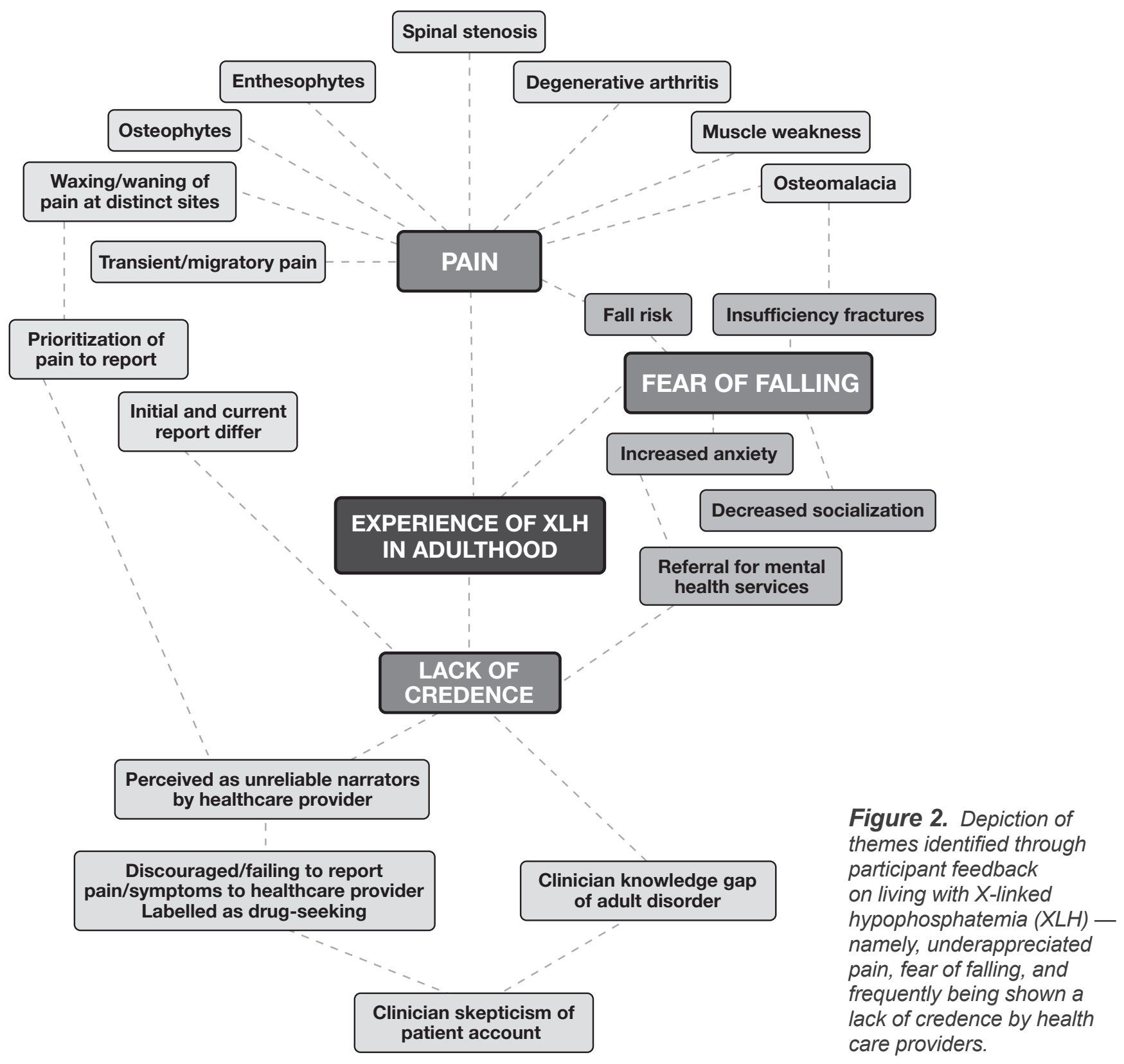

recent and current pain. Together, the variability and underreporting of symptoms reinforced the patient as an unreliable narrator. This is underscored by the validation reported by individuals when presented with physical evidence of their symptoms.

Of the themes identified in this study, the lack of credence was reported as being the most detrimental and disturbing to the participants. While participants described finding some providers with whom they had positive, trusting relationships, they generally reported a long history of encounters with providers whose care they perceived as inappropriate, dismissive, or unempathetic.

\section{Resilience and Compensation}

In contrast to fear of falling and challenges with ambulation, participants' scores on the DASH measure ${ }^{22}$ averaged 30 on a scale of 0 (no disability) to 100 (full disability), which corresponds to a disability of approximately 24\%. Participants also scored in the mid-to-high range on the COPM, both in the ability to perform skills (mean: 6.9 of 10) and in performance satisfaction with these skills (mean: 7.3 
of 10). Themes emerging from the COPM interviews conducted by OT included resilience, adaptation, and compensation, attributes which may help explain the higher than expected scores for all participants, who each self-reported arthritis and chronic pain. These generally positive attributes allowed these individuals to constantly adapt to their ever-changing physical issues but also resulted in a lack of requests by patients, as well as offers by providers, for assistance. Specific needs for adaptation were not identified by participants who were unaware of the available adaptation options. Many of those interviewed describe how, over time, they changed personal environments, tasks, and equipment used for those tasks.

The SF-36 revealed significant impact on quality of life for adults with XLH, including limitations in physical function and role, vitality, and pain (Table 4). Despite this, participants overall noted positive emotional well-being, and all participants scored in the normal or mild range on the DASS for depression, anxiety, and stress (Table 4).

\section{DISCUSSION}

Adults with XLH face ongoing and progressive functional limitations and pain as they age, ${ }^{18}$ which influences the experience of and decisions around work, travel, physical and mental health, and social and family life. ${ }^{30}$ The mixed-methods nature of the study is particularly vital given the correlation of themes emerging from this qualitative analysis with the physical findings from the functional outcome study of adults with $\mathrm{XLH},{ }^{18}$ the poorly appreciated pain and fear of falls experienced by this population, and the repeated experience of being shown a lack of credence by health care providers (Figure 2). This disconnect with providers may result in underutilization of available services and therapies and less adequate management of XLH.

Within these findings, the quantitative data from DASH and COPM, and correlation with physical findings from range of motion, gait analysis, and diagnostic imaging, validates to a large degree the participant self-reports regarding chronic and migratory pain, fractures, and fear of falling. Both the interprofessional approach and the combination of qualitative and quantitative data analyses in this study provided challenges in familiarizing research team members to methodologic and disciplinary knowledge and language, ${ }^{31}$ but also was fruitful in illuminating and aligning the physical manifestations of XLH and the narrative of adult patients.

The transient and migratory nature of pain experienced by adults with XLH, and the time constraints of patientprovider interaction, may make pain assessment more challenging for providers. While experiencing persistent pain overall, migratory and changing sites of pain may result in the patient appearing to be an unreliable narrator (Figure 2). A pattern of widespread, seemingly migratory, persistent pain has often correlated with patient reports of being labeled as demonstrating drug-seeking behavior, ${ }^{32}$ which then discourages reporting of pain, particularly to new or less-experienced providers.

Additionally, the changing nature of the pain experienced by adults with XLH raises questions about effective assessment of pain; there is much variation among patient-reported outcome measures for pain. ${ }^{33}$ Anchoring the pain scale to a "meaningful patient-reported change" (for example, 10 being passing a kidney stone or giving birth to a child) has been demonstrated to be helpful for those with chronic pain. ${ }^{33}$ Pain management for individuals with chronic pain conditions is complex ${ }^{34,35}$ and requires empathy, trust, contracting, and judicious use of pharmaceutical and nonpharmaceutical approaches. The prevalence of the presence of unrecognized fractures in this population, or the inability to differentiate fracturerelated pain from other chronic pain, suggests careful assessment and radiologic imaging, if necessary, for adequate treatment of adults with XLH.

Despite Berg balance scores being within normal limits, indicating a low risk of falls, and a typically wide stance, the fear of falling prevented participants from engaging in activities. In populations with chronic musculoskeletal changes, the fear of falling itself may be a greater predictor of future falls ${ }^{36,37}$ than the Berg balance score. Persistent osteomalacia and a compensatory analgesic gait assumed by these patients to ambulate ${ }^{18}$ predisposes individuals to falling and to fall-related fractures. A prior experience with even a single episode of fracture-related fall(s), regardless of origin, emerged as a fear of falling. Although excluded from this study, fear of falling may be additionally compounded for those individuals with XLH who 
also experience vertigo. In the $\mathrm{ABC}$ composite scores, transportation was isolated as its own parameter; confidence could be impacted by factors such as physical range of motion, ease of movement into and out of vehicle, and automotive accessibility and accommodations. Information regarding such concerns and required adaptation and/or accommodations in different modes of transportation may be helpful in future studies and in supporting independence and travel for adults with XLH.

DASS and SF-36 scores for these participants (Table 4) suggest normal to mild levels of depression, anxiety, and stress, and emotional well-being on average higher than the general population, despite the pain and debilitation associated with XLH. While the demonstrated resilience and ability to continuously adapt is noteworthy, study participants all reported lack of referrals for OT as adults because they were perceived as "dealing with it all." However, their selfdirected changes may not be the most appropriate adaptations. In childhood, a 504 plan or individualized education program may mandate OT in school. However, the physical limitations resulting from XLH do not occur until well into adulthood, when these individuals are balancing work, family, and leisure tasks. The expertise of an OT should be considered as an integral part of the health care team to offer shortand long-term solutions, which can provide improved body mechanics, functional skills, and quality of life and reduced risk of falls. ${ }^{38}$

\section{Limitations}

As with other qualitative studies, small sample size limits generalizability, though findings triangulate with concerns raised by XLH adults at advocacy events and on social media. And smaller sample size is not unusual in studying rare disease populations. Imaging and gait analysis revealed significant homogeneity of physical findings across this sample, ${ }^{18}$ which likely extends to the adult population with XLH.

Findings may reflect participants' motivation and willingness/confidence to travel and engage in a daylong functional outcome study; thus, these may not fully reflect the XLH adult population. All participants were able to travel, had completed some college or beyond, were employed or previously employed, and had welldeveloped social support (subjectively defined by participants and self-reported during interview), which also may correlate with the lower levels of depression, anxiety, and stress reported and the greater expression of resiliency espoused by participants. Participants primarily reported physical limitations that impacted their socialization and leisure activities, both in COPM assessment and interviews.

All participants were white, identified as male or female gender, and presented a range of socioeconomic, educational, and employment status at the time of assessment. The heterogeneity of the XLH population has been minimally explored. ${ }^{39}$ The racial/ethnical homogeneity of study participants further limits this study's generalizability. It does, however, remove a confounding variable pervasive in the health care field regarding perceptions concerning certain ethnicities not experiencing/reporting pain in the same manner or being more likely to be labeled as "drug-seeking."

\section{Recommendations}

Recommendations of appropriately trained PT and OT providers could greatly benefit this community with time-saving and injury-avoiding maneuvers and reduce the need for patients to create their own tools (eg, dressing hooks, driving assistance tools, pain management methods). In addition, these professionals may assist in managing pain, frustration, and isolation while maximizing independence and self-confidence, thus removing many of the avenues leading to social isolation and depression. Similarly, the pain, fear of falling, and concerns for the future experienced by adults with XLH might be managed or ameliorated with social work or psychological interventions such as mindfulness practices, ${ }^{41}$ cognitive-behavioral skills, ${ }^{42}$ and supportive counseling. The unique challenges of having a rare disorder can multiply psychosocial challenges $^{43}$ and make knowledgeable mental health providers hard to find. Peer support and mentorship ${ }^{44}$ whether online, in person, or through patient advocacy organizations can be important in promoting coping and in sharing strategies for self-care and adaptation.

Appropriate referrals, as well as provider awareness and understanding of the diagnosis and implications of XLH in adulthood, are key. New clinical recommendations for individuals across the lifespan with $\mathrm{XLH}^{45}$ will be helpful as, in the past, guidelines have focused primarily on pediatric disease. ${ }^{6}$ As a 
Table 5. X-Linked Hypophosphatemia (XLH) Resources for Patients and Providers

\begin{tabular}{|c|c|}
\hline Patient advocacy and information & $\begin{array}{l}\text { - XLH Network - https://www.xlhnetwork.org/ } \\
\text { - Association for Individuals With Vitamin D-Resistant Hypophosphatemic Rickets } \\
\text { (RVRH-XLH Europe) - http://www.rvrh.fr } \\
\text { - National Organization for Rare Disorders - https://rarediseases.org/ } \\
\text { - Global Genes - https://globalgenes.org/ }\end{array}$ \\
\hline XLH treatment information & $\begin{array}{l}\text { - A clinician's guide to X-linked hypophosphatemia (Carpenter et al) } \\
\text { - Clinical practice recommendations for the diagnosis and management of X-linked } \\
\text { hypophosphatemia (Haffner et al) } \\
\text { - Therapeutic management of hypophosphatemic rickets from infancy to adulthood } \\
\text { (Linglart et al) } \\
\text { - Patient resource on Crysvita }{ }^{\circledR 7} \text { (Ultragenyx Pharmaceutical Inc., Novato, CA) - } \\
\text { https://www.crysvita.com/ }\end{array}$ \\
\hline Additional resources & $\begin{array}{l}\text { - Little People of America's suggestions for adaptive equipment and } \\
\text { automotive accessibility - https://www.Ipaonline.org/index.php?option=com } \\
\text { content\&view=article\&id=24 } \\
\text { - AbleData database - } \underline{\text { https://abledata.acl.gov/ }} \\
\text { - Association for Driver Rehabilitation Specialists' certified driving rehab specialist } \\
\left.\text { (CDRS }{ }^{\circledR}\right) \text { certification - https://www.aded.net/ } \\
\text { - International Pain Foundation's pain management resource - } \\
\text { - } \text { https://internationalpain.org/x-linked-hypophosphatemia-xlh/ } \\
\text { Rare disease peer support - https://themighty.com/topic/rare-disease/ }\end{array}$ \\
\hline
\end{tabular}

patient tool, such guidelines can define more clearly what can be expected by adults with XLH when seeking help, assist patients to avoid unsafe and inappropriate interventions, and reduce the significant hesitation and mistrust adults with XLH experience when seeking services. Health care providers who are unfamiliar with the diagnosis must be willing to forego assumptions or biases, utilize the available clinical guidelines and recommendations, and reach out for accurate resources for this patient population (Table 5). Education resources regarding the transition from pediatric to adult-oriented care, as well as appropriate protocols for PT and OT, are still needed. Holistic care by an interprofessional team is vital for adults with XLH.

\section{CONCLUSIONS}

While advances in treatment may ease the burden for this and future generations of adults with X-linked hypophosphatemia, increasing provider awareness of the disease across the care team and ongoing research related to appropriate and safe intervention is required. Additional longitudinal research is needed to assess the trajectory of XLH across the adult lifespan and the impact of changing treatments. This cross-sectional study provides an important glimpse into the health status, care, and experience of adults with XLH, and serves to better inform health care providers of the unique needs of this population.

\section{Patient-Friendly Recap}

-While some physical effects of X-linked hypophosphatemia (XLH) are identifiable in childhood, symptoms and complications of this disease continue to progress in adulthood.

- Representing multiple disciplines relevant to XLH care, the authors interviewed adults with $\mathrm{XLH}$ to learn not only their physical limitations but also their impressions from a lifetime of health care experiences.

- They found that adults with XLH live with chronic pain, harbor a fear of falling, and face a lack of credence by health providers pertaining to their symptoms.

- To better assess adults with XLH and to avoid injury, increasing provider education in general and referral to trained multidisciplinary health care teams are recommended.

\section{Acknowledgments}

The authors acknowledge Master of Social Work students Sophie Masur, Alessandra Screnci, Glenna Vine, and Daron Dey and occupational therapy student Stevi Rehncy for data collection and preliminary analysis; Drs. Richard S. Feinn and Katherine M. McLeod for helpful discussion; and, most importantly, the XLH community for their participation and support of this work. 


\section{Author Contributions}

Study design: Macica, Meriano, Doyle. Data acquisition or analysis: all authors. Manuscript drafting: all authors. Critical revision: Hughes, Macica, Doyle.

\section{Conflicts of Interest}

None.

\section{References}

1. McKusick VA. Mendelian Inheritance in Man: Catalogs of Autosomal Dominant, Autosomal Recessive, and X-Linked Phenotypes. Baltimore, MD: The Johns Hopkins Press, 1966.

2. Carpenter TO. New perspectives on the biology and treatment of X-linked hypophosphatemic rickets. Pediatr Clin North Am. 1997;44:443-66. CrossRef

3. Endo I, Fukumoto S, Ozono K, et al. Nationwide survey of fibroblast growth factor 23 (FGF23)-related hypophosphatemic diseases in Japan: prevalence, biochemical data and treatment. Endocr J. 2015;62:811-6. CrossRef

4. Beck-Nielsen SS, Brock-Jacobsen B, Gram J, Brixen K, Jensen TK. Incidence and prevalence of nutritional and hereditary rickets in southern Denmark. Eur J Endocrinol. 2009;160:491-7. CrossRef

5. Macica CM. Overview of phosphorus-wasting diseases and need for phosphorus supplements. In: Uribarri J, Calvo MS (eds). Dietary Phosphorus: Health, Nutrition, and Regulatory Aspects. Boca Raton, FL: CRC Press, 2017.

6. Carpenter TO, Imel EA, Holm IA, Jan de Beur SM, Insogna KL. A clinician's guide to X-linked hypophosphatemia. J Bone Miner Res. 2011;26:1381-8. CrossRef

7. Francis F, Hennig S, Korn B, et al. A gene (PEX) with homologies to endopeptidases is mutated in patients with X-linked hypophosphatemic rickets. Nat Genet. 1995;11:130-6. CrossRef

8. Francis F, Strom TM, Hennig S, et al. Genomic organization of the human PEX gene mutated in X-linked dominant hypophosphatemic rickets. Genome Res. 1997;7:573-85. CrossRef

9. Rowe PS, Oudet CL, Francis F, et al. Distribution of mutations in the PEX gene in families with X-linked hypophosphataemic rickets (HYP). Hum Mol Genet. 1997;6:539-49. CrossRef

10. Shimada T, Hasegawa H, Yamazaki Y, et al. FGF-23 is a potent regulator of vitamin $\mathrm{D}$ metabolism and phosphate homeostasis. J Bone Miner Res. 2004;19:429-35. CrossRef

11. Liang G, Katz LD, Insogna KL, Carpenter TO, Macica CM. Survey of the enthesopathy of X-linked hypophosphatemia and its characterization in Hyp mice. Calcif Tissue Int. 2009;85:235-46. CrossRef

12. Liang G, Vanhouten J, Macica CM. An atypical degenerative osteoarthropathy in Hyp mice is characterized by a loss in the mineralized zone of articular cartilage. Calcif Tissue Int. 2011;89:151-62. CrossRef

13. Cremonesi I, Nucci C, D'Alessandro G, Alkhamis N, Marchionni S, Piana G. X-linked hypophosphatemic rickets: enamel abnormalities and oral clinical findings. Scanning. 2014;36:456-61. CrossRef

14. Mills ES, Iorio L, Feinn RS, Duignan KM, Macica CM. Joint replacement in X-linked hypophosphatemia. J Orthop. 2019;16:55-60. CrossRef

15. Insogna $\mathrm{KL}$, Briot $\mathrm{K}$, Imel $\mathrm{EA}$, et al. A randomized, doubleblind, placebo-controlled, phase 3 trial evaluating the efficacy of burosumab, an anti-FGF23 antibody, in adults with X-linked hypophosphatemia: week 24 primary analysis. J Bone Miner Res. 2018;33:1383-93. CrossRef
16. Skrinar A, Dvorak-Ewell M, Evins A, et al. The lifelong impact of X-linked hypophosphatemia: results from a burden of disease survey. J Endocr Soc. 2019;3:1321-34. CrossRef

17. Che H, Roux C, Etcheto A, et al. Impaired quality of life in adults with X-linked hypophosphatemia and skeletal symptoms. Eur J Endocrinol. 2016;174:325-33. CrossRef

18. Steele A, Gonzalez R, Garbalosa JC, et al. Osteoarthritis, osteophytes, and enthesophytes affect biomechanical function in adults with X-linked hypophosphatemia. J Clin Endocrinol Metab. 2020;105(4):dgaa064. CrossRef

19. Covic T, Cumming SR, Pallant JF, et al. Depression and anxiety in patients with rheumatoid arthritis: prevalence rates based on a comparison of the Depression, Anxiety and Stress Scale (DASS) and the Hospital, Anxiety and Depression Scale (HADS). BMC Psychiatry. 2012;12(1):6. CrossRef

20. Kosinski M, Keller SD, Hatoum HT, Kong SX, Ware Jr JE. The SF-36 Health Survey as a generic outcome measure in clinical trials of patients with osteoarthritis and rheumatoid arthritis: tests of data quality, scaling assumptions and score reliability. Med Care. 1999;37(5 suppl):MS10-22. $\underline{\text { CrossRef }}$

21. Dyer N, Sorra JS, Smith SA, Cleary PD, Hays RD. Psychometric properties of the Consumer Assessment of Healthcare Providers and Systems (CAHPS ${ }^{\circledR}$ ) clinician and group adult visit survey. Med Care. 2012;50 suppl:S28-34. CrossRef

22. Gummesson C, Atroshi I, Ekdahl C. The disabilities of the arm, shoulder and hand (DASH) outcome questionnaire: longitudinal construct validity and measuring self-rated health change after surgery. BMC Musculoskelet Disord. 2003;4(1):11. CrossRef

23. Law M, Baptiste S, McColl M, Opzoomer A, Polatajko H, Pollock N. The Canadian occupational performance measure: an outcome measure for occupational therapy. Can J Occup Ther. 1990;57:82-7. CrossRef

24. Doyle M, Macica C. The experience of XLH in adulthood: biopsychosocial assessment, needs, and concerns. (abstr.) J Bone Miner Res. 2017;32(suppl 1):S284.

25. Rehncy S, Macica C, Meriano C. Occupational performance of clients with rare disease. (abstr.) Presented at American Occupational Therapy Association's 2016 Annual Conference and Expo, April 7-10, 2016, in Chicago, Illinois.

26. Powell LE, Myers AM. The Activities-Specific Balance Confidence (ABC) Scale. J Gerontol A Biol Sci Med Sci. 1995;50A(1):M28-34. CrossRef

27. O'Brien BC, Harris IB, Beckman TJ, Reed DA, Cook DA. Standards for reporting qualitative research: a synthesis of recommendations. Acad Med. 2014;89:1245-51. CrossRef

28. Berg KO, Wood-Dauphinee SL, Williams JI, Maki B. Measuring balance in the elderly: validation of an instrument. Can J Public Health. 1992;83 Suppl 2:S7-11.

29. Lovibond PF, Lovibond SH. The structure of negative emotional states: Comparison of the Depression Anxiety Stress Scales (DASS) with the Beck Depression and Anxiety Inventories. Behav Res Ther. 1995;33:335-43. CrossRef

30. Smith-Young J, Solberg S, Gaudine A. Constant negotiating: managing work-related musculoskeletal disorders while remaining at the workplace. Qual Health Res. 2014;24:217-31. CrossRef

31. Driedger SM, Gallois C, Sanders CB, Santesso N. Finding common ground in team-based qualitative research using the convergent interviewing method. Qual Health Res. 2006;16:1145-57. CrossRef 
32. Buchman DZ, Ho A, Illes J. You present like a drug addict: patient and clinician perspectives on trust and trustworthiness in chronic pain management. Pain Med. 2016;17:1394-406. CrossRef

33. Goldsmith ES, Taylor BC, Greer N, et al. Focused evidence review: psychometric properties of patient-reported outcome measures for chronic musculoskeletal pain. J Gen Intern Med. 2018;33:S61-70. $\underline{\text { CrossRef }}$

34. Nuckols TK, Anderson L, Popescu I, et al. Opioid prescribing: a systematic review and critical appraisal of guidelines for chronic pain. Ann Intern Med. 2014;160:38-47. CrossRef

35. Tobin DG, Andrews R, Becker WC. Prescribing opioids in primary care: safely starting, monitoring, and stopping. Cleve Clin J Med. 2016;83:207-15. CrossRef

36. Gazibara T, Kurtagic I, Kisic-Tepavcevic D, et al. Falls, risk factors and fear of falling among persons older than 65 years of age. Psychogeriatrics. 2017;17:215-23. CrossRef

37. Jamison M, Neuberger GB, Miller PA. Correlates of falls and fear of falling among adults with rheumatoid arthritis. Arthritis Rheum. 2003;49:673-80. CrossRef

38. Di Monaco M, Vallero F, De Toma E, De Lauso L, Tappero R, Cavanna A. A single home visit by an occupational therapist reduces the risk of falling after hip fracture in elderly women: a quasi-randomized controlled trial. J Rehabil Med. 2008;40:446-50. CrossRef

39. Whyte MP, Schranck FW, Armamento-Villareal R. X-linked hypophosphatemia: a search for gender, race, anticipation, or parent of origin effects on disease expression in children. J Clin Endocrinol Metab. 1996;81:4075-80. CrossRef
40. Shavers VL, Bakos A, Sheppard VB. Race, ethnicity, and pain among the U.S. adult population. $J$ Health Care Poor Underserved. 2010;21:177-220. CrossRef

41. Chiesa A, Serretti A. Mindfulness-based interventions for chronic pain: a systematic review of the evidence. J Altern Complement Med. 2011;17:83-93. CrossRef

42. Peterson EW. Using cognitive behavioral strategies to reduce fear of falling: a matter of balance. Generations. 2002;26(4):53-9.

43. Nunn R. "It's not all in my head!" - The complex relationship between rare diseases and mental health problems. Orphanet $J$ Rare Dis. 2017;12(1):29. CrossRef

44. Doyle M. Peer support and mentorship in a US rare disease community: findings from the Cystinosis in Emerging Adulthood study. Patient. 2015;8:65-73. CrossRef

45. Haffner D, Emma F, Eastwood D, et al. Clinical practice recommendations for the diagnosis and management of X-linked hypophosphatemia. Nat Rev Nephrol. 2019;15:435-55. CrossRef

46. Binkley JM, Stratford PW, Lott SA, Riddle DL. The Lower Extremity Functional Scale (LEFS): scale development, measurement properties, and clinical application. North American Orthopaedic Rehabilitation Research Network. Phys Ther. 1999;79:371-83.

47. Linglart A, Biosse-Duplan M, Briot $K$, et al. Therapeutic management of hypophosphatemic rickets from infancy to adulthood. Endocr Connect. 2014;3:R13-30. CrossRef

(C) 2020 Aurora Health Care, Inc.

\section{CME Accreditation and Credit Designation Statements}

\begin{abstract}
Advocate Aurora Health is accredited by the Accreditation Council for Continuing Medical Education (ACCME) to provide continuing medical education for physicians. Aurora Health Care designates this journal-based CME article for a maximum of 1.00 AMA PRA Category 1 credit $^{\text {Th }}$. Physicians should claim only the credit commensurate with the extent of their participation in the activity.
\end{abstract}

To earn CME credit for this article, visit https://cme.advocateaurorahealth.org/ content/giving-credence-experience-x-linked-hypophosphatemia to access and complete the online quiz. 